\title{
Fourier transform infrared spectroscopy of dental unit water line biofilm bacteria
}

\author{
Iram Liaqat * \\ Department of Microbiology and Molecular Genetics, University of the Punjab, Quaid-e-Azam \\ Campus, Lahore, Pakistan
}

\begin{abstract}
Fourier transform-infrared (FT-IR) spectroscopy has become an important tool for rapid analysis of complex biological samples. The infrared absorbance spectrum could be regarded as a "fingerprint" which is a feature of biochemical substances. The FT-IR spectra of fresh and stored dried samples of six bacterial isolates (Klebsiella sp., Bacillus cereus, Bacillus subtilis, Pseudomonas aeruginosa, Achromobacter xylosoxidans and Achromobacter sp.) were observed by variation in sample preparation. The results indicated that variation in sample preparation did not affect the spectra of isolates. However, less promiment/absence of a small shoulder peak at $1738 \mathrm{~cm}^{-1}$ was evident in fresh dried samples of Achromobacter sp. and A. xylosoxidans compared to prominent and broad shoulder band at $1724 \mathrm{~cm}^{-1}$ in stored dried samples of these two isolates. In addition to the established $\mathrm{KBr}$ pellet technique, attenuated total reflectance (ATR) spectroscopy was used to analyse the spectra of planktonic growth $\left(-80^{\circ} \mathrm{C}\right.$ liquid cultures) and biofilm growth of six isolates. ATR spectroscopy of $-80^{\circ} \mathrm{C}$ planktonic and biofilm growth showed variation in absorption spectra in fingerprint $\left(1200-900 \mathrm{~cm}^{-1}\right)$ region. Two clear absorption bands were prominent in biofilm at 1175 and $1143 \mathrm{~cm}^{-1}$ whereas, one prominent broad band at $1075 \mathrm{~cm}^{-1}$ resulting from the overlapping of two band was noted in planktonic cultures. Biofilm forming capability of the six isolates was also determined by acridine orange staining method. The microscopic analysis of biofilms formed on glass slides revealed the presence of a matrix of exopolysaccharides and microcolonies typical of biofilm architecture. Maximum biofilm formation was observed after $175 \mathrm{~h}$ in P. aeruginosa and Klebsiella sp.
\end{abstract}

Keywords: FT-IR analysis, planktonic, biofilm, DUWL bacterial isolates, acridine orange staining

\section{Introduction}

Microbial biofilm formation in dental unit water lines (DUWL) is common and has become a serious threat to clinical dentistry. In addition to the environmental bacteria, dental unit tubings have also been recognized to be contaminated with some opportunistic pathogens [15]. A wide range of organisms has been isolated from DUWL by traditional cultivation techniques and include fungi, free-living amoebae, protozoa, nematodes and human pathogens, such as Pseudomonas aeruginosa, Legionella pneumophila, Mycobacteria species and Staphylococcus species [5].

Presently there exist a number of methods for study of bacterial microorganisms. These methods include amplification of nucleic acids by polymerase chain reaction (PCR) [32], and mass spectrometry

\footnotetext{
${ }^{*}$ Corresponding author: Iram Liaqat, Institute of Molecular Biology and Biotechnology, The University of Lahore, 1-KM Raiwind Road, Lahore, Pakistan. E-mail: iramliaq@ hotmail.com.
} 
[19], etc. However, there is still a need to study those bacteria that pose a risk to public heath. The study of bacteria by vibrational spectroscopies such as Fourier transform infrared spectroscopy (FT-IR) was pioneered by Naumann et al. [11]. Since then, FT-IR and Raman spectroscopy have been developed by several research groups to explore many features of whole microorganisms [2] and have been used to identify cellular components of both pathogenic and non-pathogenic bacteria [24]. Raman spectroscopy has been used as a powerful tool whole cell bacterial study. However, compared to FT-IR, this approach is still not sufficiently developed [34].

FT-IR spectroscopy has become a useful technique and an effective analytical tool for analysing the chemical composition of biological samples. The principle of FT-IR is based on the vibrational motions of atoms and chemical bonds within organic molecules. When a beam of light containing the mid-IR radiation band is passed through a sample, light energy from the photons is absorbed by bonds and transformed into vibrational motions [18]. Absorption in this region is mostly due to the vibrational and rotational motions of molecules and therefore used as 'fingerprint' of the sample [11]. Different bonds absorb light at different frequencies giving very specific absorption patterns to various biological components. The mid-infrared region $\left(4000-800 \mathrm{~cm}^{-1}\right)$ provides the most important information biologically [29].

A key advantage of infrared spectroscopy is that FT spectrometers are able to measure infrared spectra with accuracy in both absorbance and wavenumber of typically about one part in $10^{4}$. This, together with long-term constancy and reproducibility, even very small differences in the composition of biological materials can be consistently measured and used as a basis for classification and discrimination [34]. FT-IR spectra of bacteria are specific to a given strain and show the spectral characteristics of cell components, such as lipids, carbohydrates, membrane and intracellular proteins, polysaccharides and nucleic acids (DNA/RNA). The possibilities of inducing FT-IR spectra are inadequate due to overlapping of absorption bands specific to specific components of a bacterial cell [4].

Precise and efficient sample preparation is critical for subsequent spectral acquisition by FT-IR spectroscopy [23]. Another concern is to ensure that the sensitivity of the FT-IR analysis is in accordance with regulatory standards for chemical characterisation of pathogenic bacteria. Sample preparation methods, FT-IR accessories, and chemometrics all have been considered important in improving the efficiency of the characterisation of environmental as well as pathogenic bacteria [22]. This study compares the planktonic growth of isolates with biofilm form using attenuated total reflectance (ATR) FT-IR. ATR spectroscopy has been described as an excellent technique to investigate biofilm formation because it may be used to study the chemical composition of smooth surfaces without disrupting the biofilm substratum/liquid interface [6].

FT-IR spectra of bacteria are specific to a given strain and show the spectral characteristics of cell components, such as lipids, carbohydrates, membrane and intracellular proteins, polysaccharides, and nucleic acids (DNA/RNA). The possibilities of inducing FT-IR spectra are inadequate due to overlapping of absorption bands specific to specific components of a bacterial cell [4]. The objectives of this study were therefore: (1) to determine the effect of sample preparation on IR-spectra of DUWL biofilm isolates (2) to find the ability of ATR FT-IR to distinguish two different modes (planktonic and biofilm) of isolates. Additionally biofilm forming capability of isolates was determined using acridine orange staining. The research was conducted on the Bacillus subtilis, B. cereus, Achromobacter xylosoxidans, Achromobacter sp., Klebsiella sp. and Pseudomonas aeruginosa strains. 


\section{Materials and methods}

\subsection{Strains and growth conditions}

The six bacterial strains used in this study were Klebsiella sp. (DQ989215), Bacillus cereus (DQ989214), Bacillus subtilis (DQ989210), Pseudomonas aeruginosa (DQ989211), Achromobacter xylosoxidans (DQ989213) and Achromobacter sp. (DQ989212), which were grown in 100-ml LuriaBertani (LB) medium (10 g bacto tryptone (Difco, UK), $5 \mathrm{~g}$ yeast extract (Difco, UK) and $10 \mathrm{~g} \mathrm{NaCl}$ ) to early stationary phase $(18 \mathrm{~h})$. Cell densities were adjusted to an optical density of $\left(\mathrm{OD}_{600}=1.8\right)$, which corresponded to a population of about $3.10 \times 10^{9} \mathrm{CFU} / \mathrm{ml}$. The $\mathrm{pH}$ of LB medium was adjusted to 7 by using $10 \mathrm{mM}$ HEPES (Fisher Scientific, UK) buffer. All cultures were grown at $37^{\circ} \mathrm{C}$ with agitation at $175 \mathrm{rpm}$.

\subsection{Sample preparation}

Bacteria were harvested aseptically by centrifugation at $5000 \times g$ for $30 \mathrm{~min}$ and at $4^{\circ} \mathrm{C}$. All strains were prepared in triplicate. First replicate of each strain was washed twice with $0.85 \% \mathrm{NaCl}$, while the second and third replicates were washed with cold, sterile $20 \mathrm{mM}$ phosphate buffer saline (PBS) (pH 7.5) and ultra-high purity (UHQ) water, respectively. Each replicate was suspended into its respective washing solution, divided into three equal volumes and centrifuged again at $11,000 \times g$ for $10 \mathrm{~min}$ at $4{ }^{\circ} \mathrm{C}$. The washed cells were finally resuspended to a concentration of $100 \mathrm{mg}$ wet cells per $\mathrm{ml}$ of respective washing solution ( $\mathrm{NaCl}$, PBS or UHQ). Each preparation was then, subjected to oven drying $\left(60^{\circ} \mathrm{C}\right.$ for $30 \mathrm{~min}$ ), freeze drying (Super Modulo, Edwards High Vacuum International, Crawley, Sussex, England) for $24 \mathrm{~h}$ to a final pressure of $10-20 \mathrm{mmHg}(1.3-2.7 \mathrm{~Pa}$ ) and rotavapor drying (Eppendorf Concentrator $5301, \mathrm{UK})$ at $30^{\circ} \mathrm{C}$ for $12 \mathrm{~h}$ independently before FT-IR measurement. The same procedure was repeated again to obtain the FT-IR spectra of stored dried samples. The only difference was that pellet was stored at $-80^{\circ} \mathrm{C}$ for $48 \mathrm{~h}$ and subjected to oven during, freeze drying and rotavapor drying before IR spectroscopy.

\subsection{FT-IR spectra of fresh and stored dried DUWL samples}

For FT-IR in the absorbance mode, cell samples washed in three were ways (PBS, $0.85 \% \mathrm{NaCl}$ and DHQ) and subjected to three methods (oven drying, freeze drying and rotavapor drying) were mixed with $\mathrm{KBr}$ (BDH, AnalR; UK), used as dry finely ground powder in a Micro sampling cup (Spectra-Tech Inc., USA). FT-IR studies were performed using a Perkin-Elmer (Model 2000) with a total of up to 100 scans using a scan range of 4000 and $450 \mathrm{~cm}^{-1}$ and at $4 \mathrm{~cm}^{-1}$ resolution. Other details of spectra acquisition were mentioned previously [10].

\subsection{FT-IR spectra of planktonic and biofilm growth of DUWL isolates}

To obtain attenuated total reflectance (ATR) of the planktonic cultures, bacterial strains were grown in LB supplemented with 50\% glycerol stored till mid log phase and stored at $-80^{\circ} \mathrm{C}$ for $48 \mathrm{~h}$, harvested bacterial cultures $\left(1 \mathrm{mg} \mathrm{ml}^{-1}\right)$ were dried on a Ge-crystal and the absorption spectra between 4000 and $700 \mathrm{~cm}^{-1}$ were taken using attenuated total reflectance on a FT-IR spectrometer. All spectra were presented in the region of $2000-800 \mathrm{~cm}^{-1}$. 
Biofilm formation of six isolates was monitored following modification of [12]. Briefly $250 \mu \mathrm{l}$ of overnight cultures in $\mathrm{LBG}$ medium $\left(\mathrm{OD}_{600}=0.424 \pm 0.007\right)$ were transferred to $25 \mathrm{ml}$ fresh medium (1:100). After vortexing, $200 \mu \mathrm{l}$ were transferred into the wells of a polystyrene tissue-culture-treated 96-well microtiter plate (Corning no. 3595, UK), covered with sealing tape and incubated at $30^{\circ} \mathrm{C}$ and $100 \mathrm{rpm}$. After $175 \mathrm{~h}$, the growth medium was discarded and microtitre plate wells were washed three times with $200 \mu \mathrm{l}$ of $0.85 \%$ (w/v) $\mathrm{NaCl}$ to remove loosely attached bacteria. The biofilm was scratched from the wells of microtitre plate with the help of sterile tooth pick, applied in the form of paste on ATR-crystal and subsequently air dried for $30 \mathrm{~min}$. ATR spectra were then obtained as outlined above.

\subsection{Acridine orange staining of DUWL biofilm}

Inocula for the cells were prepared as mention above for DUWL biofilm. Sterile glass slides were aseptically placed into batch tubes along with $25 \mathrm{ml}$ of the inoculated LBG medium and incubated at $30^{\circ} \mathrm{C}$ for 48,96 and $175 \mathrm{~h}$. The glass slides were removed, rinsed with PBS and stained with $0.01 \%$ acridine orange (Sigma Chemical, St. Louis, MO, $30 \mathrm{mg} / \mathrm{ml}$ ) for $3 \mathrm{~min}$. Then, glass slides were rinsed $2 \times$ with PBS and examined with a Zeiss Axiophot microscope (Carl Zeiss, Gottingen, Germany) in fluorescence mode (FITC narrow). All images were obtained with a $\times 100$ lens objective by using attached camera (Axiocam MRC). Files for each section from top and bottom surface of glass slides were saved by computer and software package ImageJ (National Institutes of Health, Bethesda, MD) was used for image analysis. Experiment was done in triplicate.

\subsection{Data processing}

All operations on spectra were performed using original Spectrum One 3.01.00 software and saved in ASCII format, compatible with Excel (Microsoft, USA). Data was normalised to increase the intensities of band of interest and the area of selected peaks was measured by triangulation method.

\section{Results and discussion}

\subsection{FT-IR spectroscopy of fresh and stored dried DUWL samples}

Fourier transform infrared (FT-IR) has been developed for analysing many characteristics of microbiological samples [14]. FT-IR spectroscopy measures vibrations of functional groups of chemicals. The advantages of this system are minimal sample preparation, rapidity, automated, accurate, in expensive and quantitative. The absorbance spectrum generated by FT-IR contained valuable information about the chemical composition of these bacteria [33]. FT-IR spectroscopy has been demonstrated to be an effective tool to record the infrared spectrum of whole cells, such as bacteria in a film, or even, the spectrum of a single cell [29]. The six bacterial strains examined for FT-IR spectroscopy were isolated from DUWL biofilm [15]. The results for the spectra indicated that variation in sample preparation has either no/negligible effect on spectra using $\mathrm{KBr}$ disc method.

In Fig. 1(a, b), FT-IR spectra are shown in the region $3500-400 \mathrm{~cm}^{-1}$ for fresh dried samples of six strains grown in LB medium. These spectra are typical of bacteria and have been assigned previously [33]. They exhibit major bands at around $2900 \mathrm{~cm}^{-1}$ (C-H stretch), $1648 \mathrm{~cm}^{-1}$ (amide I; mainly $\mathrm{C}=\mathrm{O}$ stretch), $1548 \mathrm{~cm}^{-1}$ (amide II; N-H bend and C-N stretch), $1456 \mathrm{~cm}^{-1}$ (C-H bend), $1400 \mathrm{~cm}^{-1}$ (partially due to a symmetric stretch of the carboxylate ions), $1235 \mathrm{~cm}^{-1}(\mathrm{P}=\mathrm{O}$ asymmetric stretch, 
$\mathrm{C}-\mathrm{O}-\mathrm{C}$ stretch, and amide III (C-N bend and $\mathrm{N}-\mathrm{H}$ stretch)), and the $1150-900 \mathrm{~cm}^{-1}$ region, referred to below as the $\mathrm{PS}$ band $(\mathrm{P}=\mathrm{O}$ symmetric stretch, $\mathrm{C}-\mathrm{C}$ and $\mathrm{C}-\mathrm{O}$ stretch). The main groups of biomolecules which can be associated with these bands are proteins (amide I, II and III bands), nucleic acids (regions around 1240 and $1080 \mathrm{~cm}^{-1}$ ), polysaccharides (region from 1150 to $900 \mathrm{~cm}^{-1}$ ), and lipids (region around $2900 \mathrm{~cm}^{-1}$ ) [3]. Interestingly, it is evident from the figure that variation in sample preparation resulted in slight variation in the absorption spectra of all isolates. Spectrum is populated by absorptions arising from $\mathrm{OH}, \mathrm{C}-\mathrm{H}$ stretching vibrations of $-\mathrm{CH}_{2}$ (methylene) and $-\mathrm{CH}_{3}$ (methyl) groups. The broad bands, observed mostly in oven dried samples in the $3500-3200 \mathrm{~cm}^{-1}$ region of all samples arise, mainly from the $\mathrm{OH}$ stretching bands of water. This may be due to greater interference of water in these samples (Fig. 1). Hydration and dehydration-induced changes in protein amide bands have been assigned to structural changes of proteins in the dried state. It has also been implicated that the removal of water per se can also induce spectral changes of protein FT-IR spectra that may not be directly related with protein structural changes [35].

The main absorption bands and their peak area values under various conditions of sample treatments were plotted in Fig. 3. Fresh/stored samples washed with $\mathrm{NaCl}$ exhibited a larger peak area compared to those washed with PBS. The area of band increases in the whole region $\left(3500-400 \mathrm{~cm}^{-1}\right)$ from PBS to $\mathrm{NaCl}$ in all stored/fresh samples under various conditions of drying (freeze drying, oven drying and rotavapour drying). Region $2918 \mathrm{~cm}^{-1}$ corresponding to asymmetric stretching of $\mathrm{CH}_{2}$ mainly due to lipids region exhibited slight variation in peak area values on sample treatment with PBS and $\mathrm{NaCl}$ but this variation was noticeable among different strains (Fig. 3).

Examples of various FT-IR spectra of the bacteria collected with the $\mathrm{KBr}$ disc method of dried fresh samples are shown in Fig. 1. Minimal qualitative differences were observed between the samples under various culture conditions, however considerable quantitative differences are clearly visible between the six bacterial strains (Fig. 3). The biggest differences were found between spectra of $P$. aeruginosa, Klebsiella sp., B. subtilis and Achromobacter sp. whereas the smallest between B. subtilis and B. cereus, and A. xylosoxidans and Achromobacter sp. (Fig. 3). The findings of this study are in consistent with Catherine et al. [6], who reported minimal qualitative differences but considerable quantitative differences between B. cereus $\mathrm{C} 25$ and $B$. subtilis $\mathrm{S} 7$ using high throughput FT-IR. Increase peak area values in Klebsiella sp. at 1647, 1452, 1228 and $1077 \mathrm{~cm}^{-1}$ regions compared to $P$. aeruginosa was observed. In B. subtilis, however increased peak areas at $1395,1228,1077 \mathrm{~cm}^{-1}$ were observed compared to all other isolates (Fig. 1). Interestingly, a new peak was observed in stored/fresh dried samples of Achromobacter sp. and in fresh samples of A. xylosoxidans at $1738 \mathrm{~cm}^{-1}$ (Figs 1 and 3). Further, stored dried samples of $P$. aeruginosa and Klebsiella sp. exhibited increased peak areas at $1646 \mathrm{~cm}^{-1}$, whereas in A. xylosoxidans and Achromobacter sp., increase in peak areas was observed in fresh dried samples (Fig. 3). The strong band at $1646 \mathrm{~cm}^{-1}$ may contain a contribution from the $\mathrm{H}-\mathrm{O}-\mathrm{H}$ bending $\left(\nu_{2}\right.$ mode) band of water. However, other organic compounds including amide 1 may have IR bands in this region. Numerous other spectral features are present in this region, although unambiguous assignment of these spectral features needs further investigation by drying samples on $\mathrm{CaF}_{2}$ window at the present time.

The absorption bands $1534-1545 \mathrm{~cm}^{-1}$ corresponding amide II bands of cellular proteins respectively dominated in dried samples of all strains. The bands at 1646 and $1545 \mathrm{~cm}^{-1}$ of the fresh/stored samples showed some variations which may be linked to the variation in the proteins of cells during drying under various conditions (Fig. 3). It has already been mentioned that the bands represented an average of all the proteins in the cells, and the cells might be inactivated only from changes in a few important proteins $[2,31]$. There was a weak shoulder at $1722-1724 \mathrm{~cm}^{-1}$ corresponding to ester $\nu(\mathrm{C}=\mathrm{O})$ band, observed in fresh dried samples of Achromobacter sp. and A. xylosoxidans. While slight shifting of this shoulder 


\section{P. aeruginosa}

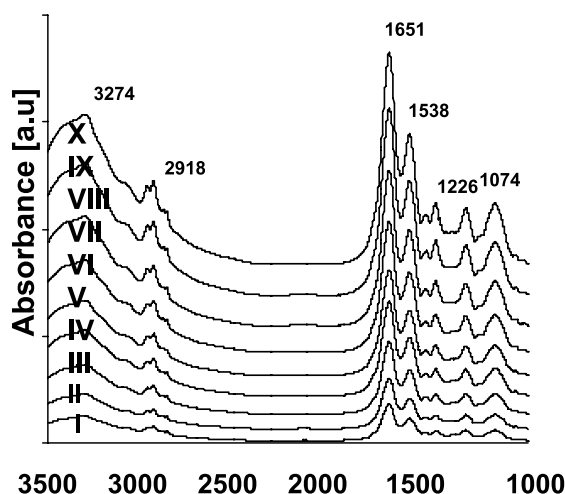

Klebsiella sp.

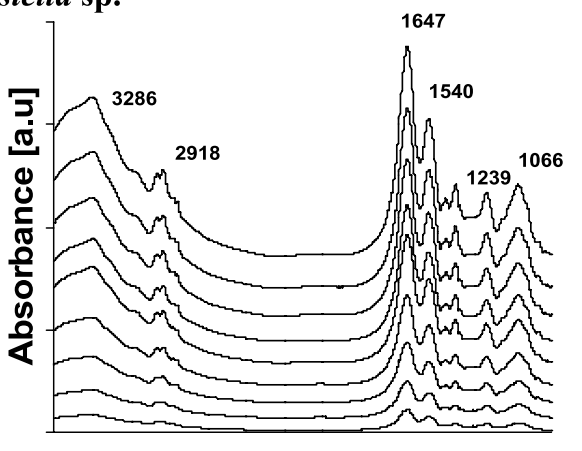

$\begin{array}{llllll}3500 & 3000 & 2500 & 2000 & 1500 & 1000\end{array}$

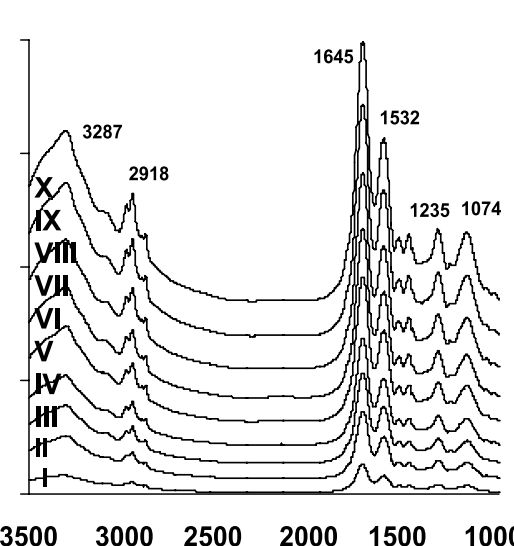

$\begin{array}{llllll}3500 & 3000 & 2500 & 2000 & 1500 & 1000\end{array}$

\section{I, $\mathrm{H}_{2} \mathrm{O}$ F.D}

II, $\mathrm{H}_{2} \mathrm{O}_{-} \mathrm{O}$

III, $\mathrm{H}_{2} \mathrm{O}^{-} \mathrm{R}$

IV, $\mathrm{NaCl}$ F. D

$\mathrm{V}, \mathrm{NaCl} \mathrm{O}$

VI, $\mathrm{NaCl}^{-} \mathrm{R}$

VII, PBS F.D

VIII, PBS $\mathrm{O}$

IX, PBS _R

\section{B. subtilis}

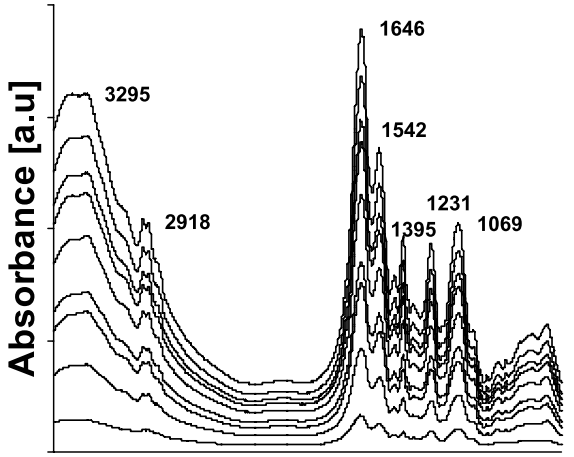

350030002500200015001000500 Wavenumber $\left[\mathrm{cm}^{-1}\right]$
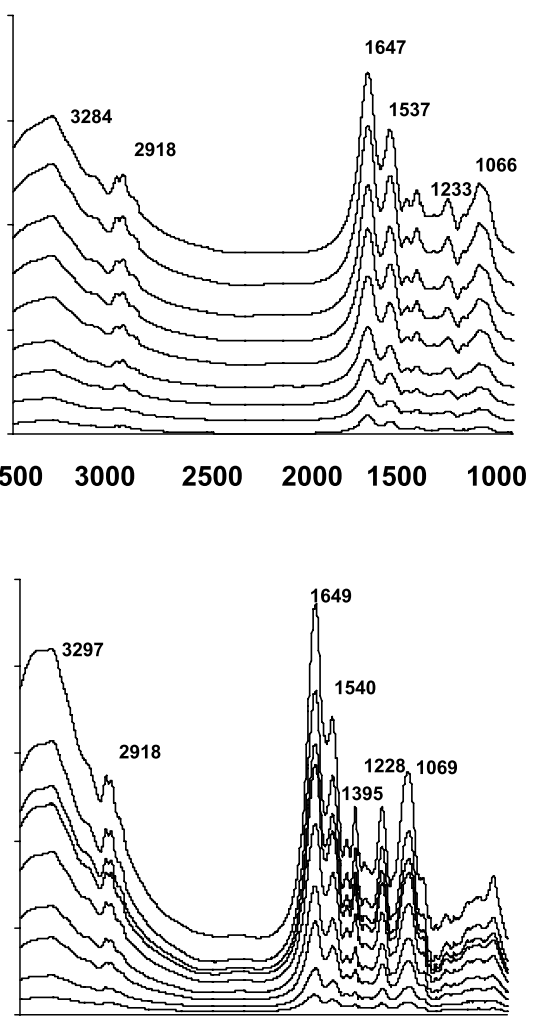

$\begin{array}{lllllll}3500 & 3000 & 2500 & 2000 & 1500 & 1000 & 500\end{array}$ Wavenumber $\left[\mathrm{cm}^{-1}\right]$

Fig. 1. (a) FT-IR spectroscopy of (I) fresh and (II) stored dried samples from six DUWL biofilm isolates. Samples were washed with $\mathrm{H}_{2} \mathrm{O}, \mathrm{NaCl}$ and $\mathrm{PBS}$ and subjected to freeze drying (F.D), oven drying $(\mathrm{O})$ and rotavapour drying (R). Data was normalized to the value 1.0 in relation to the largest absorbance value. 


\section{B.cereus}

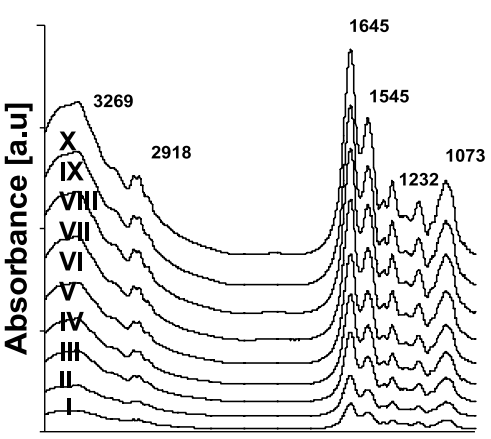

$3500300025002000 \quad 1500 \quad 1000$ Achromobacter sp.

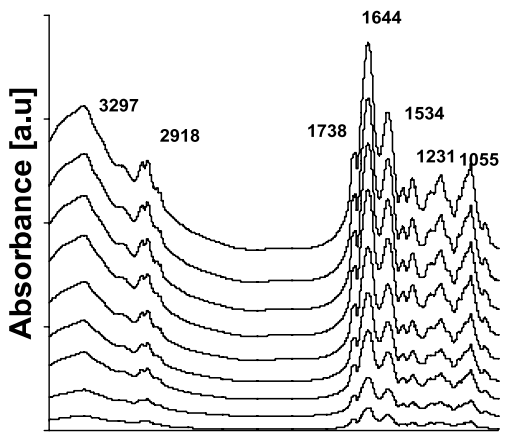
A. xylosoxidans

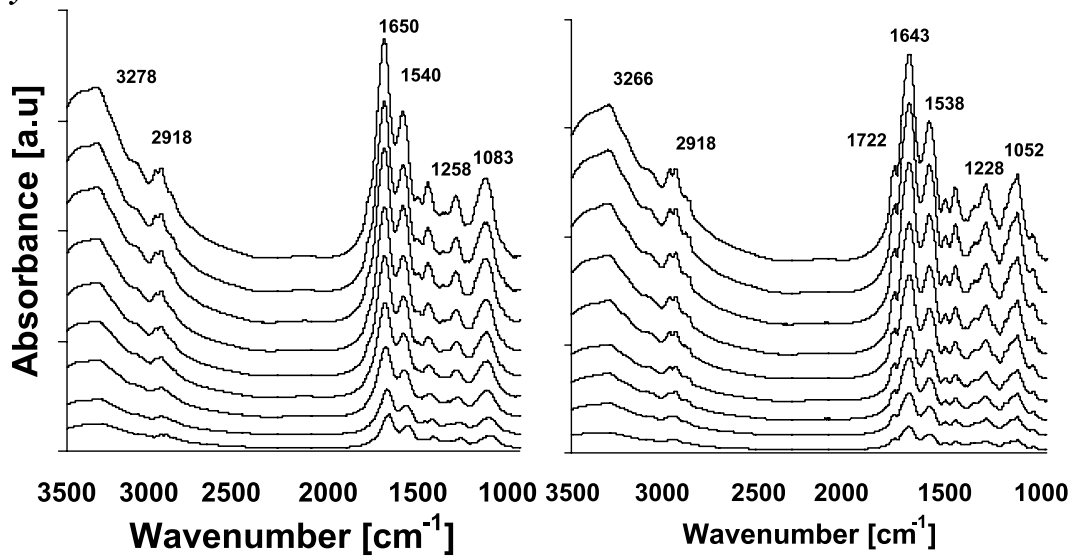

Fig. 1. (b) FT-IR spectroscopy of (I) fresh and (II) stored dried samples from six DUWL biofilm isolates. Samples were prepared in triplicates and washed independently with $\mathrm{H}_{2} \mathrm{O}, \mathrm{NaCl}$ and PBS subjected to freeze drying (F.D), oven drying (O) and rotavapour drying (R). Data was normalized to the value 1.0 in relation to the largest absorbance value. 
band to $1738 \mathrm{~cm}^{-1}$ in stored dried sample of Achromobacter sp. was observed. In A. xylosoxidans, however, it was absent (Fig. 1(b)). It has been reported earlier [1] that the position of the $\nu(\mathrm{C}=\mathrm{O})$ band under $1730 \mathrm{~cm}^{-1}$ corresponds to that of pure poly-3-hydroxybutyrate (PHB) found in many bacterial cells [31], whereas other polyhydroxyalkanoates (PHAs) exhibit bands at $1732-1740 \mathrm{~cm}^{-1}$ [20]. Considering the visible "left-hand" asymmetry of the ester $\nu(\mathrm{C}=\mathrm{O})$ band in this study with maxima at about $1724 \mathrm{~cm}^{-1}$, the presence of PHAs other than the dominating PHB is probable. Under normal nutritional conditions with aeration its biosynthesis is decreased [10]. Thus, accumulation of PHB and other PHAs in cells of bacteria under unfavourable conditions might be playing a role in bacterial tolerance to environmental stresses.

Together with an increased FT-IR absorption in the regions of $\mathrm{CH}_{2}$ bending vibrations (at 1444$1450 \mathrm{~cm}^{-1}$ ), these spectroscopic changes provide evidence for the accumulation of polyester compounds in cells of all DUWL biofilm strains (Fig. 1(a, b)). In addition, the position of a weak band was observed at $1239-1243 \mathrm{~cm}^{-1}\left(\nu_{\text {as }}\left(\mathrm{PO}_{2}^{-}\right)\right)$in fresh and stored dried sample of Klebsiella sp. and B. cereus (Fig. 1(a, b)) while $\nu_{\text {as }}\left(\mathrm{PO}_{2}{ }^{-}\right)$band shifted to $1225-1230 \mathrm{~cm}^{-1}$ in fresh/stored samples of Klebsiella sp., Achromobacter sp., A. xylosoxidans and P. aeruginosa (Fig. 1(a, b)) thus featuring the transition from the dehydrated or medium-hydrated state to a higher hydration of phosphate moieties [1].

From information obtained from previous studies [28,30], remaining IR bands were assigned as follows: in $1200-900 \mathrm{~cm}^{-1}$ spectral region shoulder like bands at 1235 and $1082 \mathrm{~cm}^{-1}$ were attributed to $\mathrm{PO}^{-2}$ asymmetric and symmetric stretching vibrations and phospholipids (Fig. 1(a, b)). The shoulder band at $1052-1064 \mathrm{~cm}^{-1}$ in all six isolates resulted from the overlap of several bands, including absorption due to the vibration modes of $\mathrm{CH}_{2} \mathrm{OH}$ and the $\mathrm{C}-\mathrm{O}$ stretching vibration coupled to the $\mathrm{C}-\mathrm{O}$ bending mode of cell carbohydrates (Fig. 1).

\subsection{Attenuated total reflectance (ATR) spectroscopy of DUWL isolates in liquid and biofilm mode}

Attenuated total reflectance (ATR) spectroscopy was used for differentiating among the spectra to obtain spectra of planktonic $\left(-80^{\circ} \mathrm{C}\right)$ liquid cultures and bacterial samples grown in biofilm mode in 96-well plates. The results showing the spectra from six isolates were presented in Fig. 2(a, b). It can be seen, like planktonic bacteria, that there is a good similarity in the spectra of these different bacterial biofilms. However, there are striking differences in cells grown. Interestingly, the band relative intensities in the spectra in the in planktonic and biofilm growth were different, and in particular, in the $1200-900 \mathrm{~cm}^{-1}$ region (amide I, II) in the biofilm spectrum and this ratio varied with the age and the physiological state of biofilm, as discussed further below. The dominant bands at $1643-1544 \mathrm{~cm}^{-1}$ observed in biofilm growth and $1637-1544 \mathrm{~cm}^{-1}$ in planktonic cultures were attributed to protein amide I and II bands. The amide band II is a vibration related to $\mathrm{N}-\mathrm{H}$ bend ${ }^{+} \mathrm{C}-\mathrm{N}$ stretch of the peptide bond [33].

The author is first to report the attenuated total reflectance-FT-IR study of DUWL isolates in biofilm mode by growing them in microtitre plates. Interestingly, in all the six samples, in both modes, there was a weak shoulder at about $1724-1736 \mathrm{~cm}^{-1}$, which indicated the accumulation of PHB and other PHAs as already reported by [1]. Since the isolates in planktonic cultures were stored at $-80^{\circ} \mathrm{C}$ as glycerol stocks for $48 \mathrm{~h}$ and in the biofilm growth, these were growing in microtitre plates without replenishing with fresh media for $175 \mathrm{~h}$. Thus, presence of this shoulder was pointing towards bacterial strategy to cope with unfavourable conditions [1]. Moreover, $\nu_{\text {as }}\left(\mathrm{PO}_{2}{ }^{-}\right)$band of cellular phosphate moieties was constantly present in all isolates in biofilm growth but it was not observed in planktonic cultures thus confirming relative instability of the state of this functional group in planktonic and biofilm mode. In 

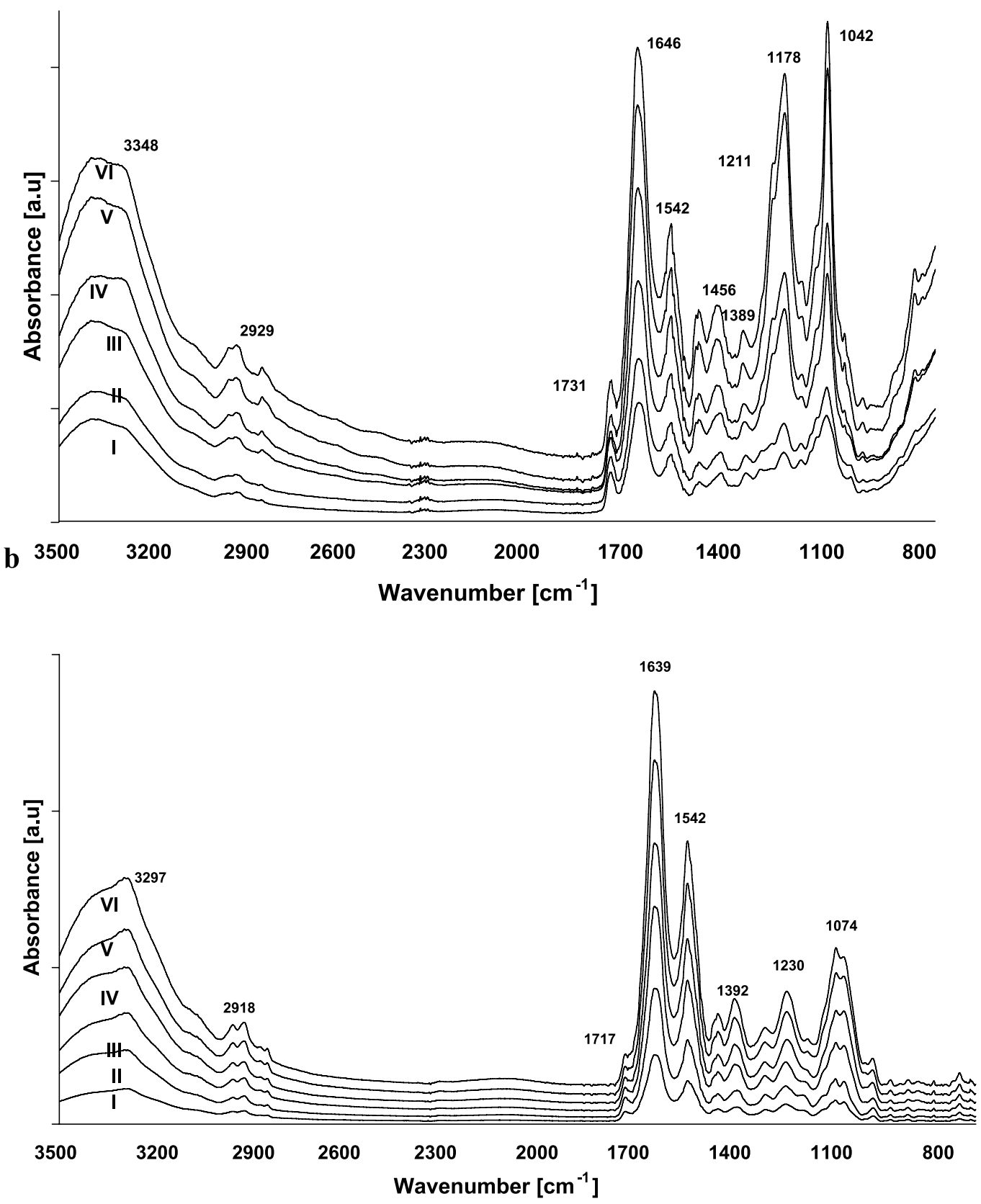

Fig. 2. Attenuated total reflectance FT-IR spectroscopy of (a) microtitre plate biofilm and (b) liquid cultures (stored at $-80^{\circ} \mathrm{C}$ ) of six DUWL isolates (I, A. xylosoxidans; II, Achromobacter sp.; III, B. cereus; IV, B. subtilis; V, P. aeruginosa; VI, Klebsiella sp.). Data was normalized to the value 1.0 in relation to the largest absorbance value. 


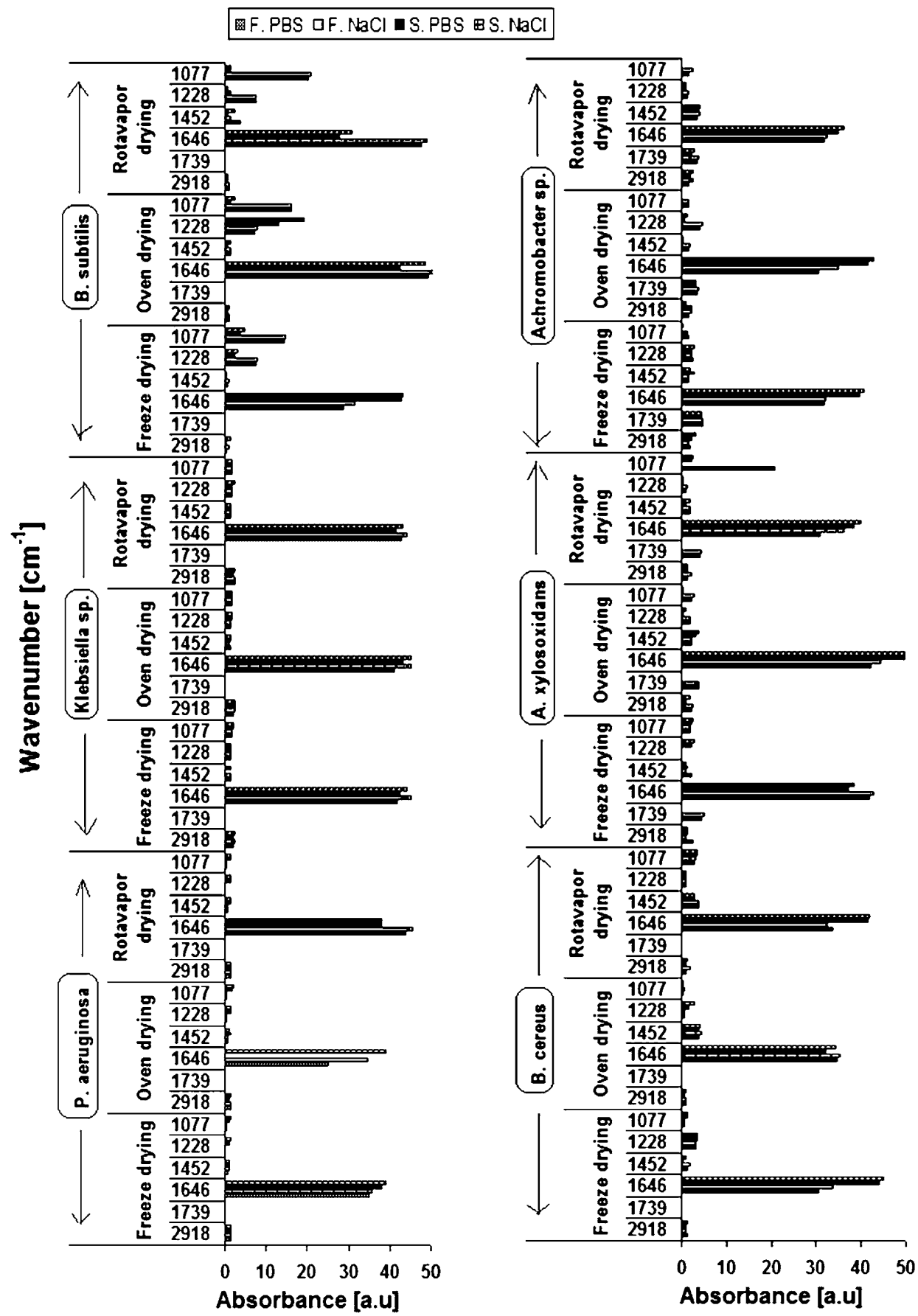

Fig. 3. The peak area alteration of selected bands of fresh and stored dried DUWL samples under various conditions (freeze drying, oven drying and rotavapour drying) of sample preparation. F.PBS, Fresh sample washed with PBS; F.NaCl, Fresh sample washed with $\mathrm{NaCl}$; S.PBS, Stored sample washed with PBS; S.NaCl, stored sample washed with $\mathrm{NaCl}$. 
a study by Yu and Irudayaraj [9], band $1453 \mathrm{~cm}^{-1}$ was predominantly found in the FT-IR spectrum of the cell envelope compared with that of the cytoplasm of bacterial cells. Based upon this observation, band $1453-1454 \mathrm{~cm}^{-1}$ should be related to membrane lipid [7]. The bands at $1394 \mathrm{~cm}^{-1}$ represents $\mathrm{C}=\mathrm{O}$ symmetric stretching of $\mathrm{COO}-[21]$ and assigned to lipids [28].

Figure 4 summarizes the differences in the peak areas of biofilm cells and planktonic cells. An increase in the peak areas at 1731,1452 and $1178 \mathrm{~cm}^{-1}$ regions was observed in biofilm cells compared to planktonic cells. Whereas increased peak areas at 2929, 1647, 1542 and $1395 \mathrm{~cm}^{-1}$ regions were observed in planktonic cells (Fig. 4). A possible origin of the observed spectral heterogeneity peaks might then be ascribed to differences in the cells growing in two different states i.e., planktonic and biofilm mode [3,13]. Absorption spectra in the $1200-900 \mathrm{~cm}^{-1}$ affected greatly during biofilm growth of bacterial isolates. Indeed, during biofilm formation the whole $1200-900 \mathrm{~cm}^{-1}$ region gradually rises (Fig. 2(a), Table 2). Whilst the stronger bands in B. subtilis might be because of the presence of teichoic acids [25], the stronger band intensities/peak areas could be attributed to the differences in metabolic state and aging of the cells during the course of biofilm formation [13]. It is also well-known that the attachment of some bacteria to surfaces and their permanent adhesion involves the formation of glycocalyx. Therefore, biofilm formation may induce the appearance of these polysaccharide fibers [25]. These results are in agreement with a previous study by Delille et al. [3], who reported the ATR-FT-IR spectra acquired over $3 \mathrm{~h}$ period of biofilm formation in P. fluorescens were similar to planktonic bacterium spectra, in particular, regarding the relative intensities and the amide II/PS band intensity ratio. They illustrated that for the amide II band, the intensity of all bands increased with time due to accumulation of biomass and an increase in the surface coverage by bacteria, further confirmed by optical microscopy. Comparison of all 6 biofilm spectra recorded shows that the spectrum recorded displays the strong absorption bands at 1043 and $1175 \mathrm{~cm}^{-1}$ in biofilm growth which mainly originates from nucleic acids (Fig. 2(a)). Further the area at $1178 \mathrm{~cm}^{-1}$ increase in biofilm mode compared to planktonic growth as shown in Fig. 4. In fact, important physiological changes in bacteria enhance their metabolic activity as soon as they become attached to a surface [13]. It might be due to an increase of the complex sugar band located between 1200-900 $\mathrm{cm}^{-1}$ which represents the extra and/or the intracellular polysaccharides [25]. In B. subtilis, stronger bands might be because of the presence of teichoic acids [27].

\subsection{Observation and analysis of biofilm by acridine orange staining}

Due to the fact, that spectral variations were observed in bacteria growing in biofilm mode, acridine orange was used to visualize the biofilm formation microscopically after $175 \mathrm{~h}$. Acridine orange, a fluorochrome strain, is potentially better in the direct microscopic examination of clinical specimens because it gives striking differential staining between bacteria and background cells and debris [14]. For all isolates, as the incubation time extended, the number of attached bacteria increased throughout the abiotic surface [24]. Figure 5(a) shows the process of colonization on glass slides, after $175 \mathrm{~h}$ following growth in inoculated LB medium. The biofilm determination on the top and bottom side of each glass slide permitted the monitoring of the microbial colonization. Strains varied in their ability to form biofilm and maximum biofilm forming capability on glass slides was observed in P. aeruginosa and Klebsiella sp. after $175 \mathrm{~h}$ (Fig. 5(a), III and VI).

The acridine orange binds with bacterial RNA and DNA and emits red (in single-stranded nucleic acid) and green (in double-stranded nucleic acid) fluorescence [16]. Cells in the log phase emit red fluorescence, whereas those in the stationary phase emit a green one. This acridine orange ability has also been used to analyse the bacterial metabolism in planktonic cells and in biofilms [17]. The DUWL isolates 


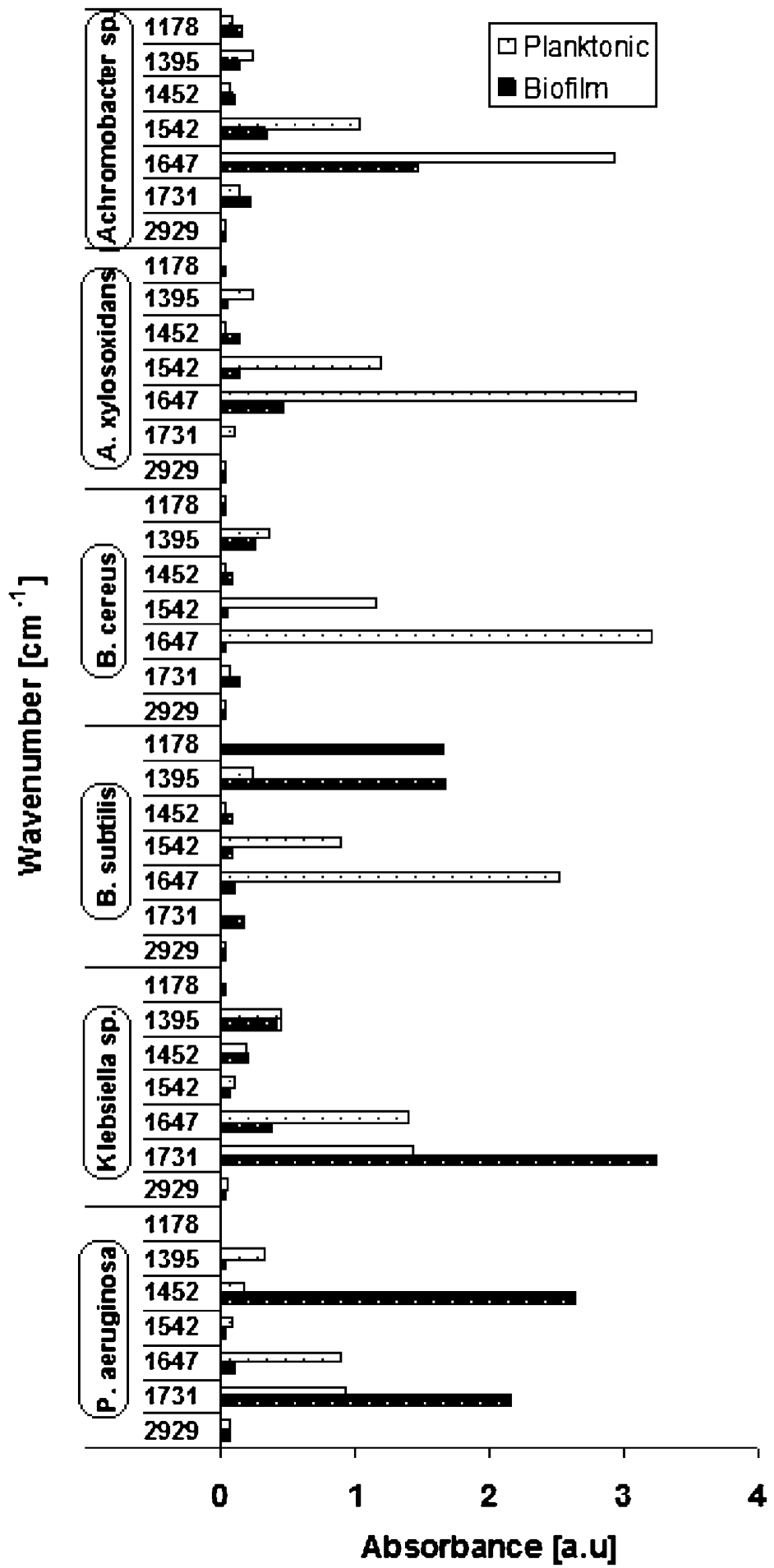

Fig. 4. The peak area alteration of selected bands of DUWL isolates in liquid and biofilm mode. 


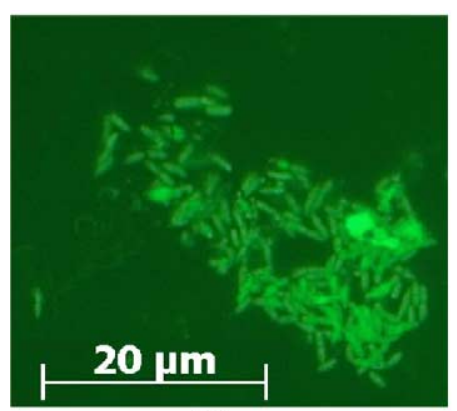

(I)

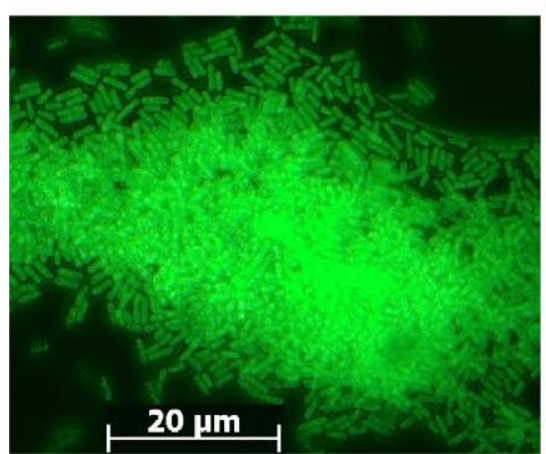

(IV)

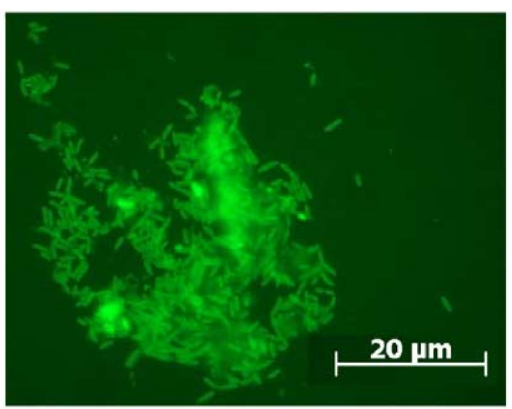

(II)

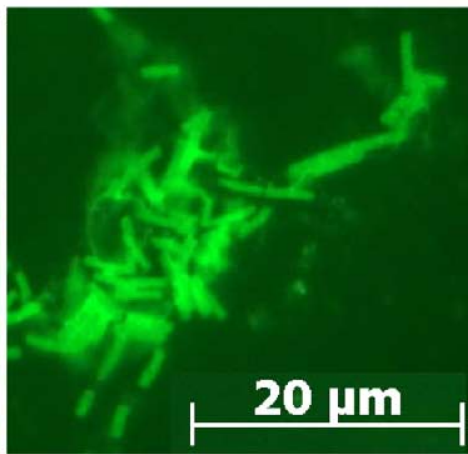

(V)

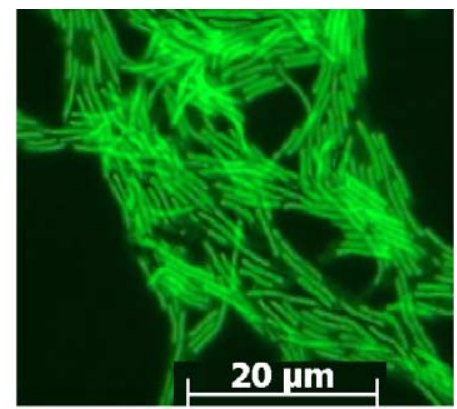

(III)

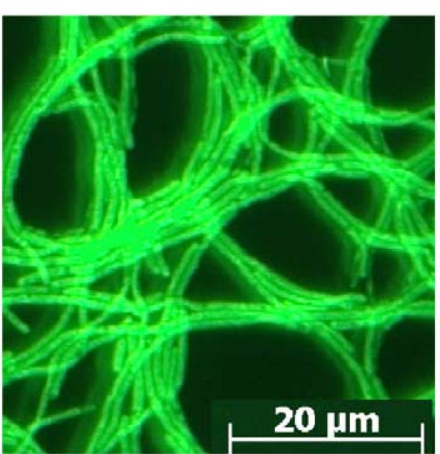

(VI)

(a)

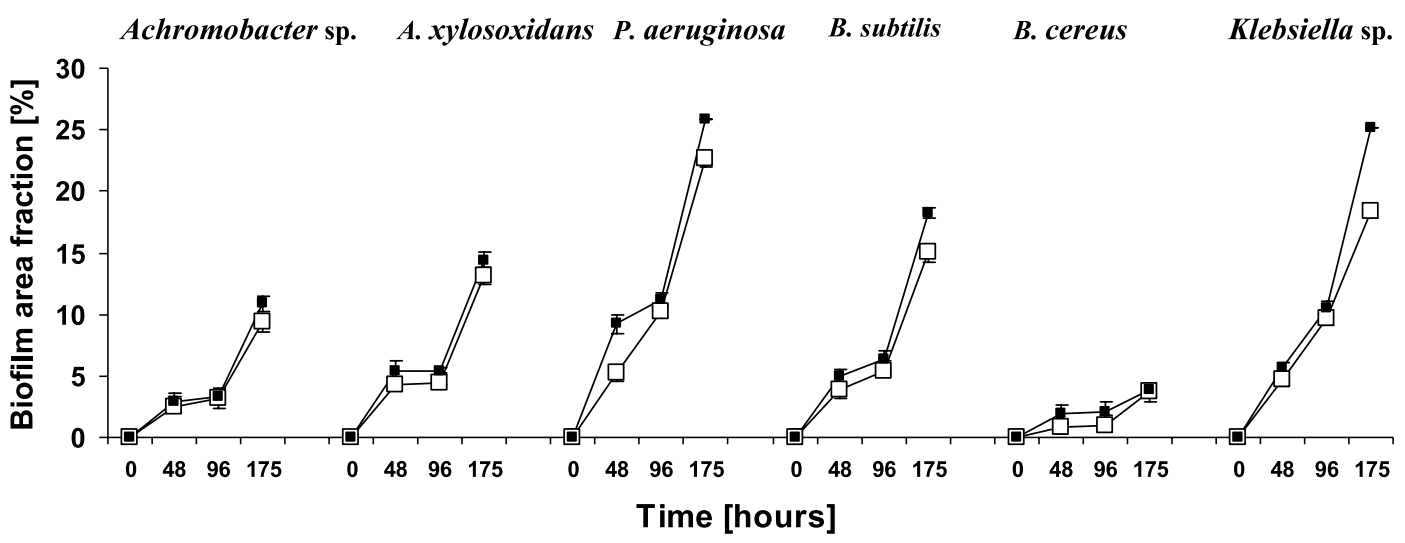

(b)

Fig. 5. (a) Acridine orange staining of biofilm formed by DUWL isolates (I) Achromobacter sp., (II) A. xylosoxidans, (III) P. aeruginosa, (IV) B. subtilis, (V) B. cereus and (VI) Klebsiella sp. on glass slides after 175 h. (b) Measurement of biofilm area coverage by six DUWL biofilm isolates on top surface $(\square)$ and bottom surface ( $\square$ ) of glass slides after 48,96 and $175 \mathrm{~h}$.

biofilm showed very high quantity of RNA in the biofilm cells, indicating high metabolic activity [24]. However, the lack of equivalent metabolic investigations regarding naturally formed oral biofilms limits the importance of this finding. Related to free-living and in vitro-grown biofilms, this could be a sign of biofilm immaturity, despite the multiplayer structure and developed matrix. The biofilm immaturity might be explained with the relatively short period of biofilm development of no more than $175 \mathrm{~h}$ (in fact 
limited by the exfoliation), depletion of nutrient supply, however, this requires further investigations.

At the first stages, the glass slides were rapidly colonized and appeared to form a monolayer biofilm. When the biofilm matured, between 96 and $175 \mathrm{~h}$ (data not shown), it was possible to differentiate some cell clusters, and rich bacterial growth was observed in the previously uncolonized zones. After $175 \mathrm{~h}$, greatly enhanced biofilm formation (\%) at the bottom surface was observed in all isolates except for B. cereus which was relatively poor biofilm former (Fig. 5(b)). At this stage a low basal layer of cells could be distinguished, with stacks of biofilm coming up from the surface in P. aeruginosa, B. subtilis, Klebsiella sp., Achromobacter sp. and A. xylosoxidans (Fig. 5(a)). The qualitative data reported here demonstrate maximum capacity to form biofilm on glass slides in Klebsiella sp. and P. aeruginosa (Fig. 5(b)). It might be due to secretion of extracellular polysaccharide matrix (EPS). EPS is thought to be an important factor for the process of bacterial attachment to abiotic surfaces [26]. EPS of biofilms consist largely of polysaccharides, in addition to nucleic acids and proteins [8]. Alternatively, the hydrophobicities and surface charges of bacteria play an important role in bacterial attachment to abiotic surfaces. These properties differ between species, serotypes or strains, and can change with variation in growth conditions, physiological state of cells, as well as composition of suspension medium [26], hence contributing to strong or relatively weak biofilm formation in different DUWL isolates.

\section{Conclusion}

In conclusion, the present study showed obtained spectra of the bacterial biofilms, pointed on several spectral bands which could be considered as unique for biofilms. These bands might be considered as reliable biomarkers to be developed for future rapid discrimination between bacteria in their biofilm growth and contribute important information in the development of persistent strains within clinical environments. This rapid discrimination could be highly significant in the case of clinical samples obtained from unidentified infections. Further studies on this aspect will be necessary to understand the mechanism of biofilm growth among DUWL isolates. In addition, acridine orange staining showed the maximum biofilm forming capability of DUWL biofilm isolates after $175 \mathrm{~h}$ on the bottom surface of glass slides. In this study, biofilm growth, however, was examined in batch cultures, not beyond $175 \mathrm{~h}$ incubation time. It is possible that increased incubation time with replenishing of fresh media would result in biofilms highly similar in terms of numbers of colonized viable cells.

\section{Acknowledgements}

The author wish to thank Robert T. Bachmann and Jesus J. Ojeda (University of Sheffield, UK) for their technical support and helpful discussions. This work was supported by scholarship awarded by Higher Education Commission (HEC), Pakistan.

\section{References}

[1] A.A. Kamnev, A.V. Tugarova, L.P. Antonyuk, P.A. Tarantilis, L.A. Kulikov, Y.D. Perfiliev, M.G. Polissiou and P.H. Gardiner, Anal. Chim. Acta 573/574 (2006), 445-452.

[2] A.C. Singer, W.E. Huang, J. Helm and I.P. Thompson, J. Microbiol. Methods 60 (2005), 417-422.

[3] A. Delille, F. Quilès and F. Humbert, Appl. Environ. Microbiol. 73 (2007), 5782-5788. 
[4] A. Bosch, M.A. Golowczyc, A.G. Abraham, G.L. Garrote, G.L. De Antoni and O. Yantorno, Int. J. Food Microbiol. 111 (2006), 280-287.

[5] C.L. Pankhurst, Risk assessment of dental unit waterline contamination, Prim. Dent. Care 10 (2003), 5-10.

[6] C.L. Winder and R. Goodacre, Analyst 129 (2004), 1118-1122.

[7] C. Santivarangkna, M. Wenning, P. Foerst and U. Kulozik, J. Appl. Microbiol. 102 (2007), 748-756.

[8] C.S. Laspidou and B.E. Rittmann, Water Res. 36 (2002), 2711-2720.

[9] C. Yu and J. Irudayaraj, Biopolymers 77 (2005), 368-377.

[10] D. Kadouri, E. Jurkevitch and Y. Okon, Appl. Environ. Microbiol. 69 (2003), 3244-3250.

[11] D. Naumann, D. Helm and H. Labischinski, Nature 351 (1991), 81-82.

[12] G.D. Christensen, W.A. Simpson, J. Younge, L.M. Baddour, F.F. Barrett, D.M. Melton and E.H. Beachey, J. Clin. Microbiol. 22 (1985), 996-1006.

[13] G.G. Geesey and D.C. Uhite, Determination of bacterial growth and activity at solid liquid interfaces, Annu. Rev. Microbiol. 44 (1990), 579-602.

[14] H. Oberreuter, J. Charzinski and S. Scherer, Microbiology 148 (2002), 1523-1532.

[15] I. Liaqat and A.N. Sabri, Curr. Microbiol. 56 (2008), 619-624.

[16] J.G. Bruno, S.A. Sincock and P.J. Stopa, Biotech. Histochem. 71 (1996), 130-136.

[17] K.D. Xu, G.A. McFeters and P.S. Stewart, Microbiology 146 (2000), 547-549.

[18] K. Hong, S. Sun, W. Tian, G.Q. Chen and W. Huang, Appl. Microbiol. Biotechnol. 51 (1999), 523-526.

[19] K.L. Wahl, S.C. Wunschel, K.H. Jarman, N.B. Valentine, C.E. Petersen, M.T. Kingsley, K.A. Zartolas and A.J. Saenz, Anal. Chem. 74 (2002), 6191-6199.

[20] K.M. Gough, D. Zelinski, W.R. Wiens, M. Rak and I.M. Dixon, Anal. Biochem. 316 (2003), 232-242.

[21] K. Maquelin, L.P. Choo-Smith, C. Kirschner, N.A. Ngo-Thi, D. Naumann and G.J. Puppels, Handbook of Vibrational Spectroscopy, Wiley, Chichester, UK, 2001.

[22] K. Maquelin, L.P. Choo-Smith, C. Kirschner, N.A. Ngo-Thi, D. Naumann and G.J. Puppels, J. Clin. Microbiol. 41 (2003), 324-329.

[23] L.M. Miller and P. Dumas, Biochim. Biophys. Acta 1758 (2006), 846-857.

[24] L. Vitkov, M. Hannig, W.D. Krautgartner, M. Herrmann, K. Fuchs, M. Klappacher and A. Hermann, Lett. Appl. Microbiol. 41 (2005), 404-411.

[25] L.A.S. Parolis, H. Parolis, G.G.S. Dutton, P.L. Wing and J.J. Skura, Carbohyd. Res. 216 (1991), 495-504.

[26] M.S. Chae, H. Schraft, H.L. Truelstrup and R. Mackereth, Food Microbiol. 23 (2006), 250-259.

[27] M. Wei, J.H. Evans, T. Bostrom and L. Grondahl, J. Mater. Sci. Mater. Med. 14 (2003), 311-320.

[28] P. Wong, S. Goldstein, R. Grekin, A. Godwin, C. Pivik and B. Riga, Cancer Res. 53 (1993), 762-765.

[29] R. Goodacre, B. Shann, R.J. Gilbert, E.M. Timmins, A.C. McGovern, B.K. Alsberg, D.B. Kell and N.A. Logan, Anal. Chem. 72 (2000), 119-127.

[30] R.K. Dukor, Handbook of Vibrational Spectroscopy, Wiley, Chichester, UK, 2001.

[31] S. Khanna and A.K. Srivastava, Process Biochem. 40 (2005), 607-619.

[32] S. Makino and H. Cheun, J. Microbiol. Methods 53 (2003), 141-147.

[33] V. Erukhimovitch, V. Pavlov, M. Talyshinsky, Y. Souprun and M. Huleihel, J. Pharm. Biomed. Anal. 37 (2005), 11051108.

[34] W.E. Huang, D. Hopper, R. Goodacre, M. Beckmann, A. Singer and J. Draper, J. Microbiol. Methods 67 (2006), $273-280$.

[35] W.F. Wolkers and H. Oldenhof, Spectroscopy 19 (2005), 89-99. 


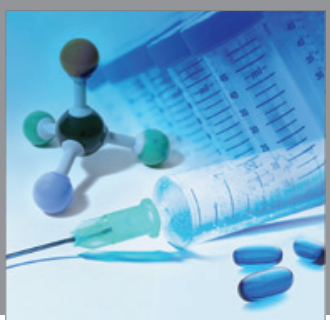

International Journal of

Medicinal Chemistry

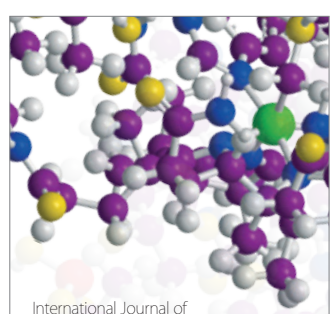

Carbohydrate Chemistry

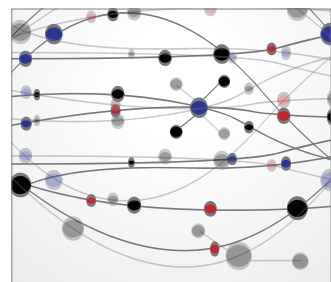

The Scientific World Journal
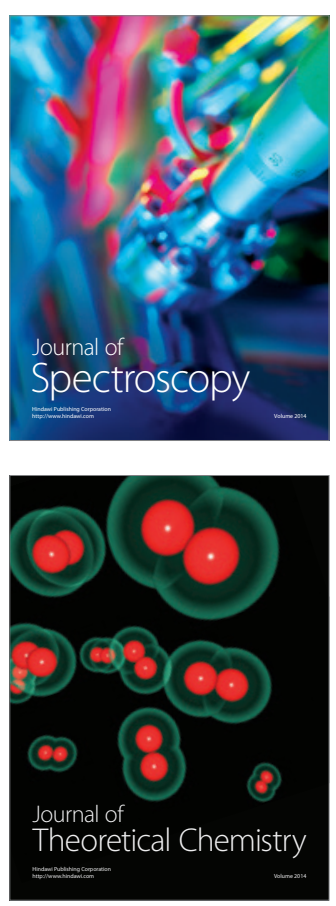
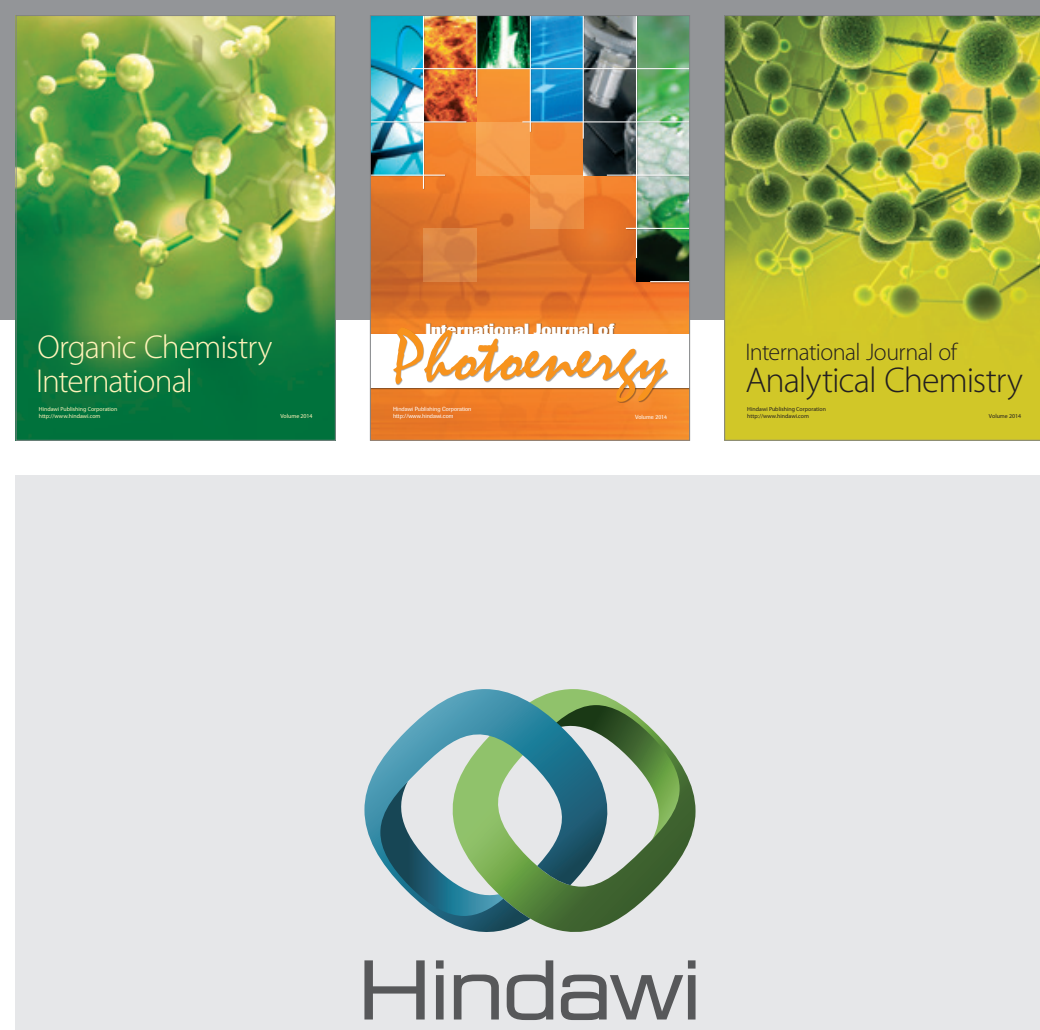

Submit your manuscripts at

http://www.hindawi.com
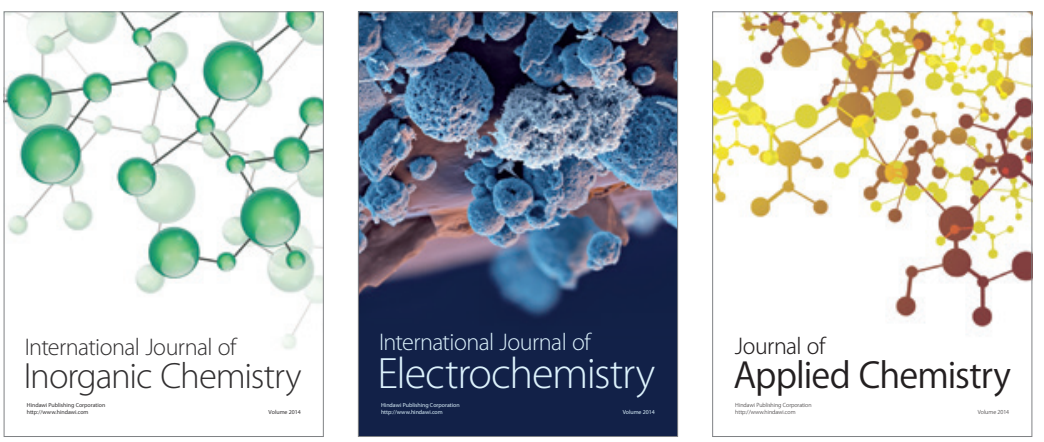

Journal of

Applied Chemistry
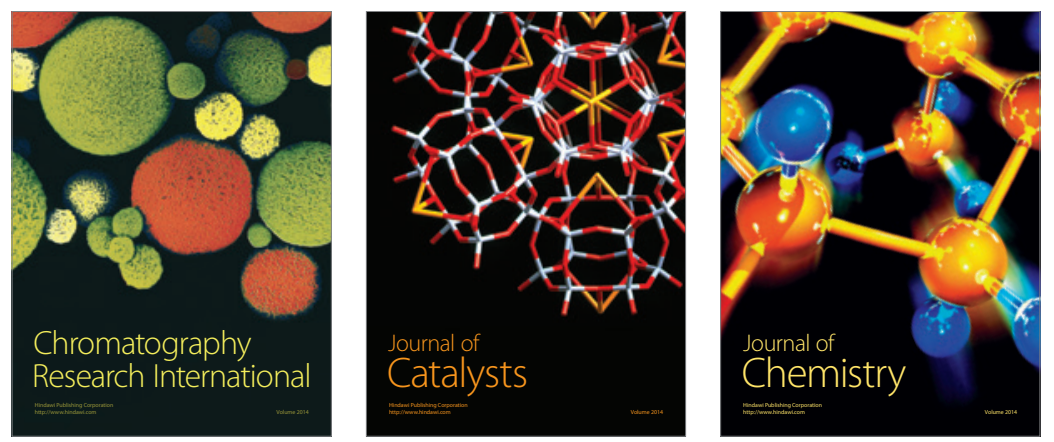
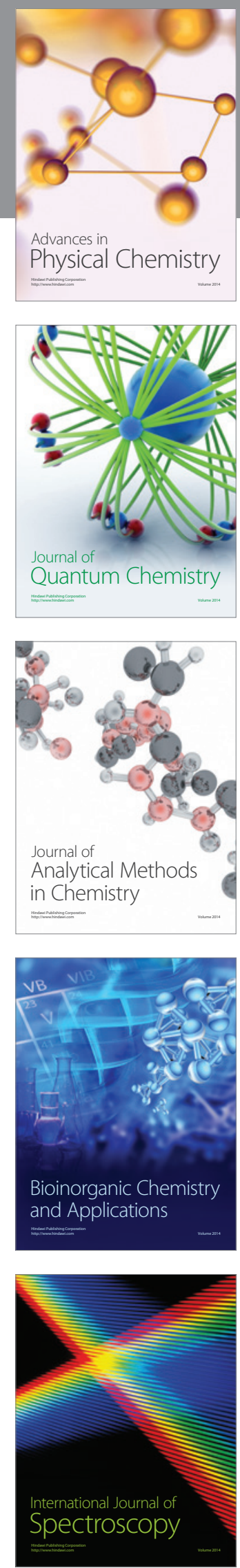